\title{
Correction to "Moment tensor inversion of early instrumental data: application to the 1917 High Tiber Valley, Monterchi earthquake” by F. Bernardi et al.
}

\author{
Fabrizio Bernardi ${ }^{1{ }^{\star}}$, Maria Grazia Ciaccio ${ }^{2}$, Barbara Palombo ${ }^{1}$, Graziano Ferrari ${ }^{3}$ \\ ${ }^{1}$ Istituto Nazionale di Geofisica e Vulcanologia, Centro Nazionale Terremoti, Rome, Italy \\ ${ }^{2}$ Istituto Nazionale di Geofisica e Vulcanologia, Sezione Roma 1, Rome, Italy \\ ${ }^{3}$ Istituto Nazionale di Geofisica e Vulcanologia, Sezione di Bologna, Bologna, Italy
}

Article history

Received and accepted July 13, 2016.

This article corrects: F. Bernardi, M.G. Ciaccio, B. Palombo and G. Ferrari, Moment tensor inversion of early instrumental data: application to the 1917 High Tiber Valley, Monterchi earthquake, Annals of Geophysics, 59 (3), 2016, S0318; doi:10.4401/ag-6850.

\section{Corrigenda}

[1] Page 1, Abstract, fourth last line: for "slip" read "rake". last line:

[2] Page 9, left column, third last and second to for "This method has been tested on some recent earthquakes." read "This method has been tested on some recent earthquakes and applied in Vannoli et al. [2015]."

[3] Page 10, left column, ninth line from bottom: for "strike/dip/slip" read "strike/dip/rake".

[4] Page 13, References:

the following reference needs to be added: "Vannoli, P., G. Vannucci, F. Bernardi, B. Palombo and G. Ferrari (2015). The source of the 30 October 1930, Mw 5.8, Senigallia (central Italy) earthquake: a convergent solution from instrumental, macroseismic and geological data, B. Seismol. Soc. Am., 105 (3), 1548-1561; doi:10. 1785/0120140263".

\footnotetext{
^Corresponding author: Fabrizio Bernardi, Istituto Nazionale di Geofisica e Vulcanologia, Centro Nazionale Terremoti, Rome, Italy; email: fabrizio.bernardi@ingv.it.

(C) 2016 by the Istituto Nazionale di Geofisica e Vulcanologia. All rights reserved.
} 